Proc. of the XI Int. Conf. - Ion Implantation and other Applications of Ions and Electrons, Kazimierz Dolny 2016

\title{
Thermal Desorption of Krypton Implanted into Silicon
}

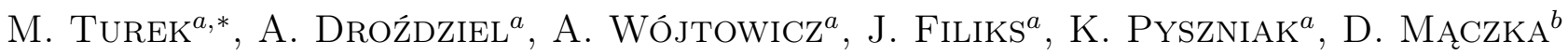 \\ AND Y. YUSCHKEVICH ${ }^{c}$ \\ ${ }^{a}$ Institute of Physics, Maria Curie-Skłodowska University in Lublin, \\ pl. M. Curie-Skłodowskiej 1, 20-031 Lublin, Poland \\ ${ }^{b}$ National Center for Nuclear Studies, A. Soltana 7, 05-400 Otwock, Poland \\ ${ }^{c}$ Joint Institute for Nuclear Research, Joliot-Curie 6, Dubna, Russia
}

\begin{abstract}
The thermal desorption spectrometry studies of krypton implanted Si samples are presented. Implantations (with the fluence $2 \times 10^{16} \mathrm{~cm}^{-2}$ ) were done with the energies 100,150 , and $200 \mathrm{keV}$. Additionally, a $200 \mathrm{keV}$ and $100 \mathrm{keV} \mathrm{Kr}{ }^{+} G$ double implantation was performed. A sudden $\mathrm{Kr}$ release was observed in the $\approx 1100-1400 \mathrm{~K}$ range, most probably coming from the gas bubbles in cavities. The desorption activation energy varies from $2.5 \mathrm{eV}$ $(100 \mathrm{keV})$ to $0.8(200 \mathrm{keV})$. The peak splitting suggests existence of two kinds of cavities trapping the implanted noble gas. Two Kr releases are observed for the 200 and $100 \mathrm{keV}$ double-implanted samples. The peak shift of the release corresponding to $100 \mathrm{keV}$ implantation could be a result of both introduced disorder and higher effective Kr concentration. The desorption activation energy is risen to $\approx 3.2 \mathrm{eV}$ for both releases.
\end{abstract}

DOI: $10.12693 /$ APhysPolA.132.249

PACS/topics: 68.43.Vx, 61.72.uf

\section{Introduction}

Thermal desorption spectroscopy (TDS) or thermal programmed desorption (TPD) using He, other inert gases or deuterium has become a popular technique enabling studies of the disorder introduced into solids during e.g. ion irradiation as the analysis of gas release spectra provides much information concerning atom diffusion, desorption and their trapping by lattice defects like vacancies and their clusters [1]. TDS spectroscopy is often used to study radiation induced damage as well as retention/release of gases like deuterium in the plasmafacing materials intended to be used in the controllable fussion devices including tungsten $[2,3]$, beryllium [4-6] or graphite [7]. The technique was often employed in the case of materials widely applied in electronics, like silicon $[8,9]$ for implanted metals $[10-12]$ as well as thin films [13-15]. Special attempts were made to study formation of bubbles (gas filled cavities) as a result of highfluence $\left(\approx 10^{16} \mathrm{~cm}^{-2}\right.$ and even more) inert gas ion implantation [8, 16-19]. The intensive studies on formation of cavities filled with gas atoms and He release from the implanted Si were focused on different factors governing these processes including implantation [8] and annealing temperatures [16] or $\mathrm{H}^{+}$ion post-implantation parameters [17].

On the other hand, thermal desorption of heavier inert gases was not so often studied, probably due to the larger atomic radius [20]. It should be also noted that the heavier the projectile, the shallower is the implanted matrix layer. The TDS spectra of argon implanted Si were obtained in a very broad range of implantation energies $(\approx 100 \mathrm{eV} \mathrm{[21],} \approx 1 \mathrm{keV}[22]$ and typical of semiconductor industry processing $(20-60 \mathrm{keV}$ [23]). It was shown [23] that implanted $\mathrm{Ar}$ atoms are in two different states in $\mathrm{Si}$ (dissolved in bulk $\mathrm{Si}$ and gathered in cavities), which re- sulted in two peaks in the TDS spectra. The presence of two kinds of peaks in the TDS spectra was also confirmed for larger implantation energy [24]. Moreover, change of peaks order appearance of corresponding to Ar release from bulk Si and gas-filled cavities was shown.

The paper is devoted to thermal desorption of even heavier inert gas, krypton, implanted into the Si samples with the energies in the range $100-200 \mathrm{keV}$. The paper presents also the brief description of the custom-made TDS setup and all experimental procedures. The TDS spectra collected for various heating rates (form $0.1 \mathrm{~K} / \mathrm{s}$ up to $0.7 \mathrm{~K} / \mathrm{s}$ ) are presented and discussed. Desorption activation energies are estimated from the peak shifts using the Redhead approach. The changes of the TDS spectra for $200 \mathrm{keV}$ and then $100 \mathrm{keV} \mathrm{Kr}$ implantation are also under investigation.

\section{Experimental}

The 100-oriented silicon samples were implanted with ${ }^{84} \mathrm{Kr}^{+}$ions using the implanter in the Institute of Physics, Lublin, equipped with the arc discharge ion source. Implantations were made with energies 100,150 , and $200 \mathrm{keV}$, the beam current density was $\approx 2-3 \mu \mathrm{A} / \mathrm{cm}^{2}$. The implantation fluences were $2 \times 10^{16}$ ions $/ \mathrm{cm}^{2}$ in every case. One of the samples was doubly implanted with $200 \mathrm{keV}$ and then $100 \mathrm{keV}$ ions, with the total fluence $4 \times 10^{16}$ ions $/ \mathrm{cm}^{2}$. Implantations were performed at room temperature.

A construction and principle of operation of the TDS spectrometer was described in detail in our previous papers $[24,25]$. However, a brief overview is given here for completeness sake. The stainless steel vacuum chamber contains the sample heater (HTR1002 Boralectric, Momentive, Strongsville OH, USA) and is equipped with quadruple mass spectrometer, vacuum meters, electrical 
feedthroughs and other supplementary equipment. The heater is shielded by $0.5 \mathrm{~mm}$ thick molybdenum screens and $2 \mathrm{~mm}$ thick stainless steel screen placed at the bottom in order to prevent the chamber from overheating. The sample heater is powered by a programmable power supply EA-PS 8080T (EA-Electro-Automatik GmbH, Viersen, Germany). It is used to heat samples with different rates up to approximately $1600 \mathrm{~K}$ (the limitation is mostly due to the fact that sample temperature is measured using the K-type thermocouple). The thermocouple is connected via the Hewlett-Packard 34970A data acquisition/switch unit to the PC-class microcomputer. An optional, contactless temperature measurement using a pyrometer is also possible. The programmable power supply is controlled by the custom-made software making the use of the PID algorithm and data from the sample temperature measurements. The schematic view of the experimental setup is presented in Fig. 1.

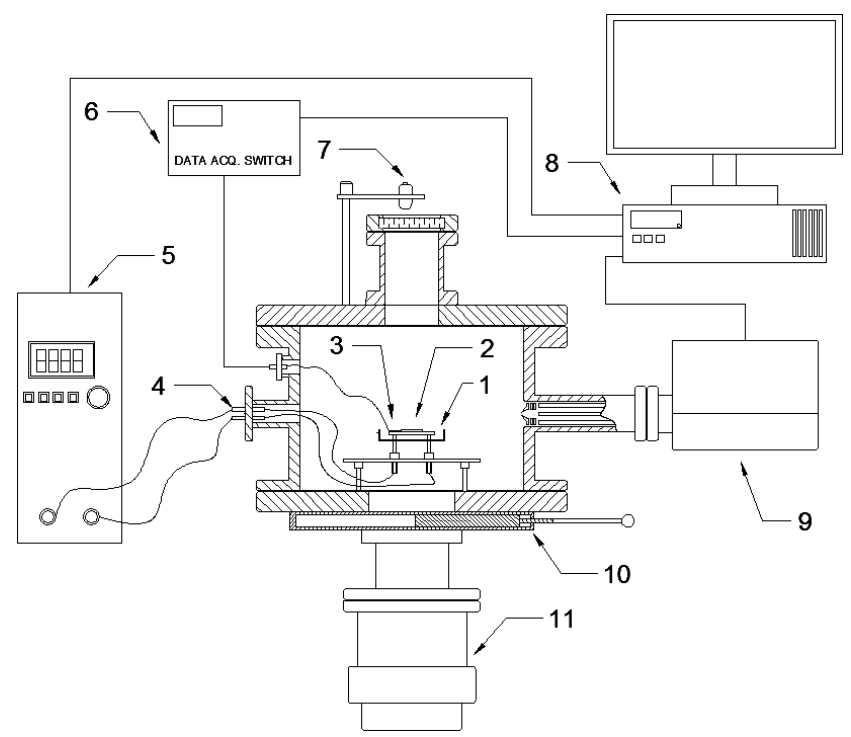

Fig. 1. Schematic view of the experimental setup: $1-$ heater, 2 - sample, 3 - thermocouple, 4 - electrical feedthrough, 5 - programmable heater power supply, 6 - data acquisition switch, 7 - pyrometer, 8 - microcomputer, 9 - quadruple mass spectrometer, 10 vacuum gatevalve, 11 - turbomolecular pump.

The base pressure (order of $10^{-7}$ mbar) was maintained during all measurements using a turbomolecular pump. It should be noted that an additional gate valve between the pump and the main chamber was added enabling also static vacuum measurements. Krypton (84 a.m.u.) released from the heated sample (area of $\approx 2 \mathrm{~cm}^{2}$ ) was detected by the QMG220 quadruple mass spectrometer (Pfeiffer Vacuum, Asslar, Germany) controlled by the Quadera ${ }^{T M}$ software. Its detection limit is approximately $2 \times 10^{-12}$ mbar for Ar.

The spectrometer was baked out prior to measurements in order to get rid of most residual gases. As in our previous papers, there was applied the isochronal sample heating profile

$$
T(t)=T_{0}+\beta t,
$$

where $T_{0}$ is room temperature and $\beta$ is the heating ramp rate. The ramp rates were changed from $0.1 \mathrm{~K} / \mathrm{s}$ up to $0.7 \mathrm{~K} / \mathrm{s}$.

\section{Results}

The implanted $\mathrm{Kr}$ depth profiles obtained using the SRIM software [26] as well as distributions of introduced damage to the sample are shown in Fig. 2. The implantation projected range changes from $\approx 60 \mathrm{~nm}(100 \mathrm{keV})$ up to $120 \mathrm{~nm}(200 \mathrm{keV})$. The thickness of the defected layer changes more or less in the same range. It should be noted that the vacancy concentration is almost the same for all implantation energies.

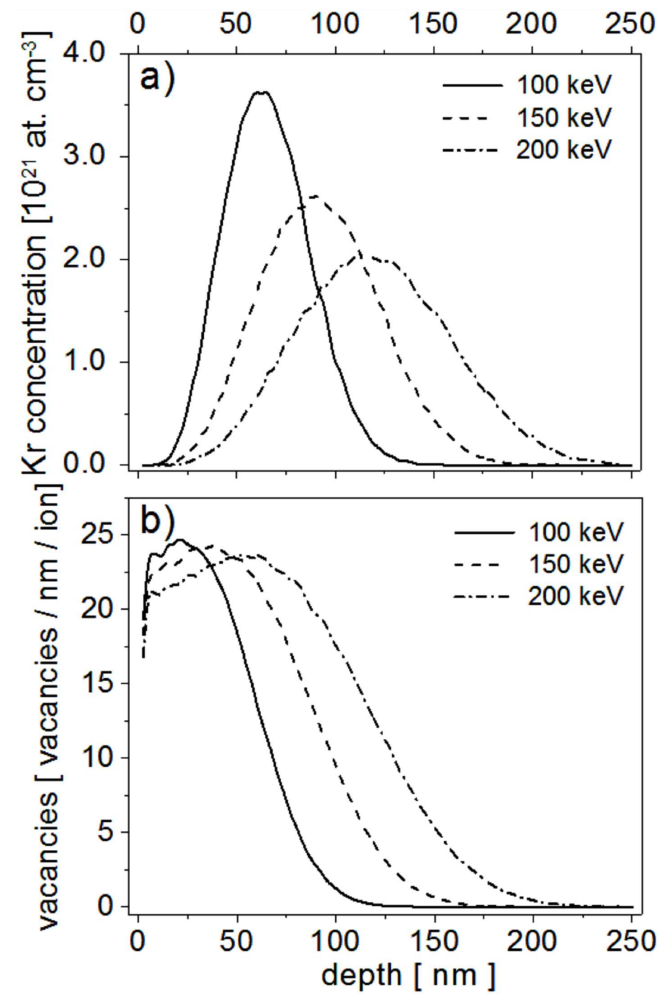

Fig. 2. Implanted $\mathrm{Kr}$ concentration (a) and damage (vacancies) distributions (b) calculated using the SRIM software.

The obtained TDS spectra are collected in Fig. 3 (the case of $E=100 \mathrm{keV})$, Fig. $4(E=150 \mathrm{keV})$ and Fig. 5 $(E=200 \mathrm{keV})$. A sudden $\mathrm{Kr}$ release is observed in the temperature range $1050-1400 \mathrm{~K}$. It should be noted that it is at least $100 \mathrm{~K}$ higher than that observed for Ar implanted with $E=115 \mathrm{keV}$ [24], and much higher than release temperatures for much more mobile He (700$800 \mathrm{~K}$ ) [25]. Such difference could be explained, for example by the above mentioned fact that Kr has larger atomic radius $(\approx 2.0 \AA)$ compared to He $(1.2 \AA)[20]$. The peak position is shifted by $\approx 200 \mathrm{~K}$ toward higher temperatures as implantation energy (and the projected range) 


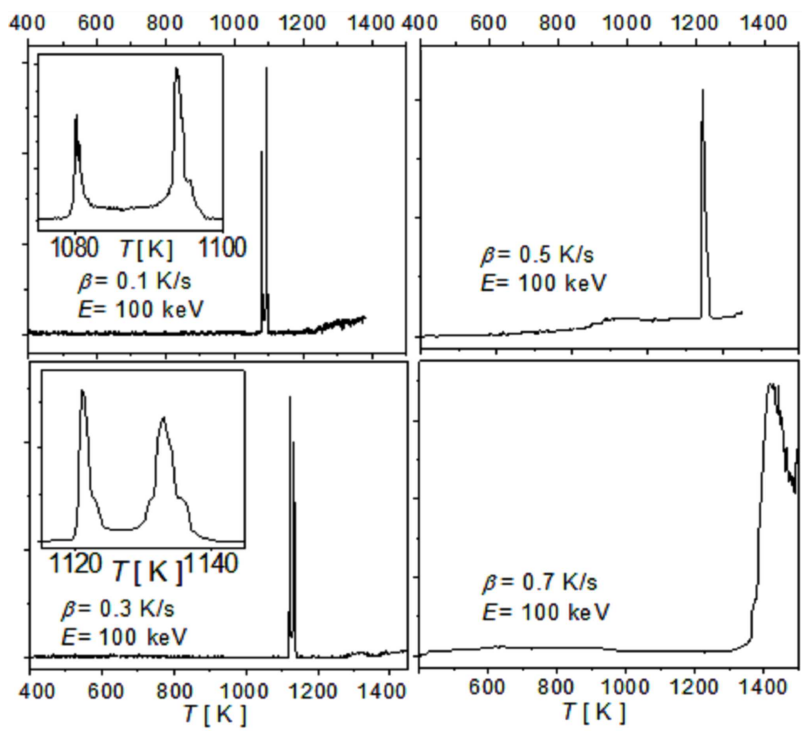

Fig. 3. TDS spectra collected for the $100 \mathrm{keV} \mathrm{Kr}{ }^{+}$implanted samples.

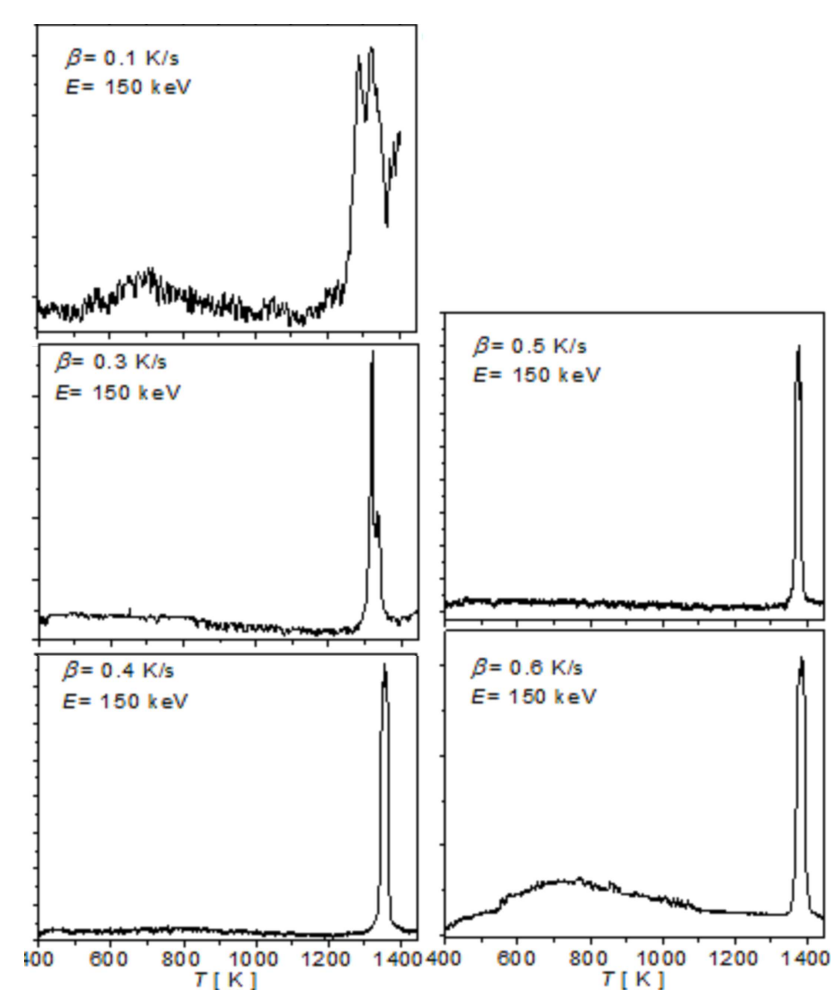

Fig. 4. TDS spectra collected for the $150 \mathrm{keV} \mathrm{Kr}{ }^{+}$implanted samples.

rises from $100 \mathrm{keV}$ to $200 \mathrm{keV}$ (the case of $\beta=0.5 \mathrm{~K} / \mathrm{s}$ ). Note that peak positions are accumulated in Table I. A rather narrow shape of the peak, especially for shallower implantations may suggest that one deals here with a sudden gas release from bubbles or gas-filled cavities. Two releases, particularly distinct for smaller ramp rates

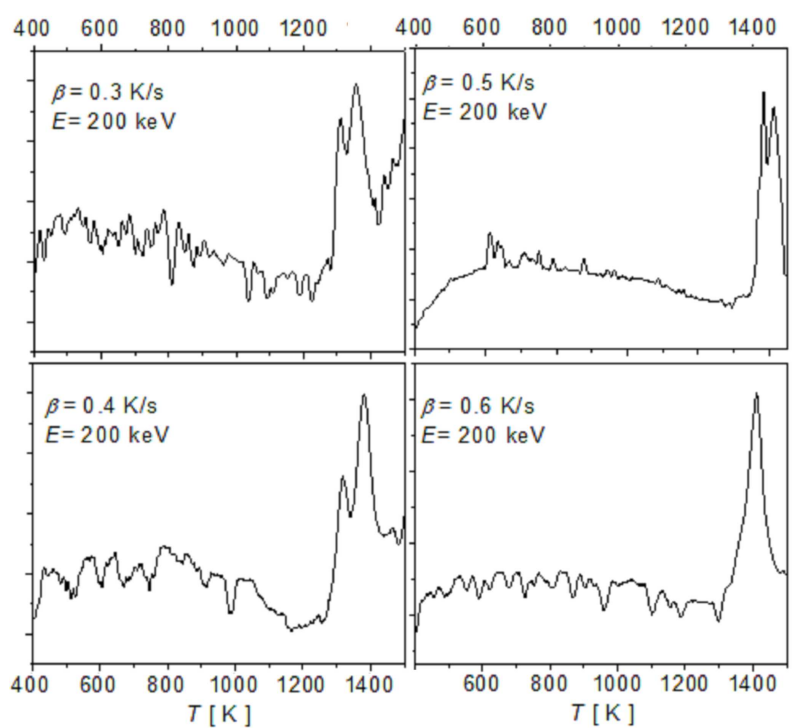

Fig. 5. TDS spectra collected for the $200 \mathrm{keV} \mathrm{Kr}^{+}$implanted samples.

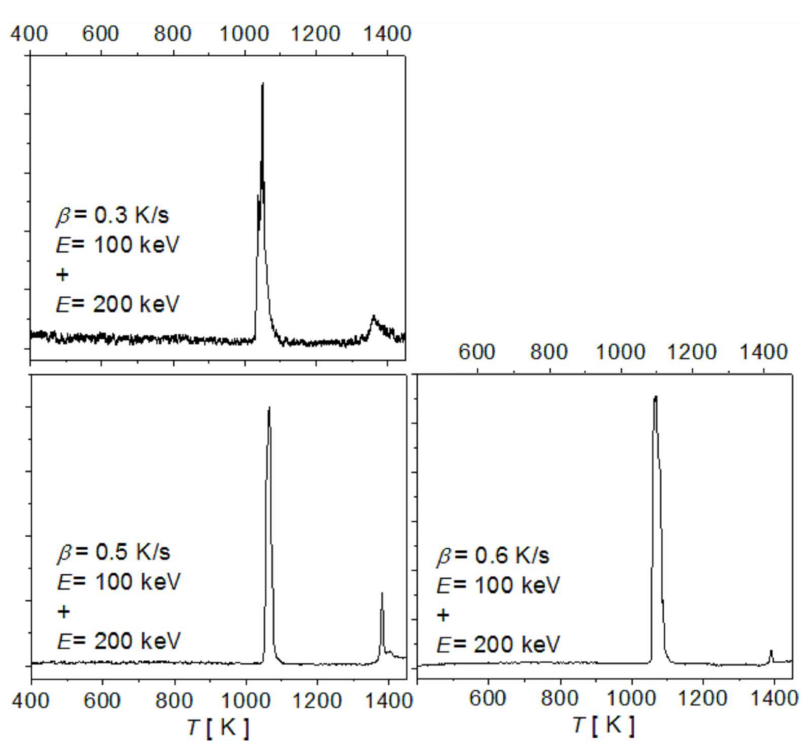

Fig. 6. TDS spectra collected for the $200 \mathrm{keV}$ and $100 \mathrm{keV} \mathrm{Kr}^{+}$double-implanted samples.

(see insets in Fig. 3) can be observed which may be due to the presence of different kinds of defects occupied by $\mathrm{Kr}$ atoms, like single vacancies, or vacancy clusters of different sizes [27]. The distance between these peaks increases with the implantation energy from $\approx 15 \mathrm{~K}$ for $E=100 \mathrm{keV}$ up to $60 \mathrm{~K}$ for $E=200 \mathrm{keV}$. It should be also noted that the release peak width increases with implantation energy which could be related to a larger projected range and implanted Kr profile width.

The peak position and its width change also with the heating ramp rate, as observed for other noble gases [8, 16-19, 24, 25]. The largest shift (almost $350 \mathrm{~K}$ 
TABLE I

Position of the Kr release peak and desorption activation energies for different implantation energies.

\begin{tabular}{|c|c|c|}
\hline \multicolumn{3}{|c|}{$E=100 \mathrm{keV}$} \\
\hline$\beta[\mathrm{K} / \mathrm{s}]$ & $T_{p}[\mathrm{~K}]$ & $Q[\mathrm{eV}]$ \\
\hline 0.1 & $1080 / 1094$ & \multirow{5}{*}{$2.5 \pm 0.16$} \\
\hline 0.3 & $1121 / 1133$ & \\
\hline 0.5 & 1145 & \\
\hline 0.7 & 1417 & \\
\hline- & - & \\
\hline \multicolumn{3}{|c|}{$E=150 \mathrm{keV}$} \\
\hline$\beta[\mathrm{K} / \mathrm{s}]$ & $T_{p}[\mathrm{~K}]$ & $Q[\mathrm{eV}]$ \\
\hline 0.1 & $1288 / 1321$ & \multirow{5}{*}{$2.6 \pm 0.6$} \\
\hline 0.3 & $1316 / 1337$ & \\
\hline 0.4 & 1358 & \\
\hline 0.5 & 1373 & \\
\hline 0.6 & 1380 & \\
\hline \multicolumn{3}{|c|}{$E=200 \mathrm{keV}$} \\
\hline$\beta[\mathrm{K} / \mathrm{s}]$ & $T_{p}[\mathrm{~K}]$ & $Q[\mathrm{eV}]$ \\
\hline 0.3 & $1307 / 1359$ & \multirow{4}{*}{$0.8 \pm 0.25$} \\
\hline 0.4 & $1318 / 1381$ & \\
\hline 0.5 & $1385 / 1414$ & \\
\hline 0.6 & 1410 & \\
\hline \multicolumn{3}{|c|}{$E=200 \mathrm{keV}+E=100 \mathrm{keV}$} \\
\hline$\beta[\mathrm{K} / \mathrm{s}]$ & $T_{p}[\mathrm{~K}]$ & $Q[\mathrm{eV}]$ \\
\hline 0.3 & $1048 / 1360$ & \\
\hline 0.5 & $1064 / 1380$ & $3.2 \pm 0.4$ \\
\hline 0.6 & $1067 / 1391$ & $3.3 \pm 0.4$ \\
\hline- & - & \\
\hline
\end{tabular}

when $\beta$ changes from $0.1 \mathrm{~K} / \mathrm{s}$ up to $0.7 \mathrm{~K} / \mathrm{s}$ ) is observed for the lowest implantation energy. The mentioned shift could be analysed in order to estimate desorption activation energy according to the Redhead method [28]. In the case of the first order process the Polanyi-Wigner equation could be written as

$$
\frac{\mathrm{d} n}{\mathrm{~d} t}=-\gamma n \exp \left(-\frac{Q}{k T}\right),
$$

where $n$ is the surface density of the desorbing gas, $k$ is the Boltzmann constant, $Q$ is the desorption activation energy and $\gamma$ is the preexponential factor. Keeping in mind that the linear heating profile (1) was assumed and referring to the temperature corresponding to the maximum of the $\beta$ peak as $T_{p}$, one gets from the condition $\mathrm{d}^{2} n / \mathrm{d} t^{2}=0$ (maximum of the gas release) the relation

$$
\frac{1}{T_{p}}=\frac{k}{Q} \ln \left(\frac{T_{p}^{2}}{\beta}\right)+\frac{k}{Q} \ln \left(\gamma \frac{k}{Q}\right) .
$$

Hence, the desorption activation energy could be easily obtained from the slope of the $1 / T_{p}$ vs. $\ln \left(T_{p}^{2} / \beta\right)$ plot. The calculated values of desorption activation energy are collected in Table I. One can see that $Q$ decreases with the implantation energy from $\approx 2.5 \mathrm{eV}(100 \mathrm{keV})$ to $0.8 \mathrm{eV}(200 \mathrm{keV})$. A similar effect was also observed for Ar [24]. The calculated $Q$ value for $E=150 \mathrm{keV}$ is slightly above that for $E=100 \mathrm{keV}$ but one keep in mind large estimated error of the former value. Then it is justified to assume that $Q$ decreases with $E$ in the considered range.

TDS measurements were also conducted for Si samples double-implanted with $200 \mathrm{keV}$ and $100 \mathrm{keV} \mathrm{Kr}^{+}$beams. In Fig. 5 the presence of two releases corresponding more or less to the main peaks observed for separate $100 \mathrm{keV}$ and $200 \mathrm{keV}$ irradiations can be found. The agreement is more accurate for $200 \mathrm{keV}$ release. Note that the signal corresponding to the layer implanted with $200 \mathrm{keV}$ is several times weaker than that of $100 \mathrm{keV}$ layer. This could be understood in the light of SRIM depth profiles in Fig. 2. The deeper $(\approx 100-200 \mathrm{~nm})$ layer affected by $200 \mathrm{keV}$ implantation contains approximately only one fourth of all implanted $\mathrm{Kr}$ atoms. The larger shift of the $100 \mathrm{keV}$ release (several tens of $\mathrm{K}$ ) may be due to the fact that the shallower layer $(0-100 \mathrm{keV})$ is characterised by vacancy concentration twice as much as the layer affected by the $200 \mathrm{keV}$ implantation only (see Fig. 2b). However, it should be stressed that $\mathrm{Kr}$ double implantations induced peak shift toward lower temperatures is contrary to the effect of the disorder introduced by Si self-implantation. However, this could be explained based on the fact that double implantation increases the effective $\mathrm{Kr}$ concentration in the shallower (up to $100 \mathrm{~nm}$ ) layer leading to the faster pressure buildup in vacancy clusters or cavities. The Redhead analysis was applied to both peaks of the TDS spectra from the double-implanted samples. The desorption activation energy is increased due to the introduced disorder for both cases up to $\approx 3.2 \mathrm{eV}$.

It is an open question whether a small release of $\mathrm{Kr}$ is observed as a very broad and low peak near 600-800 K. This signal could be e.g. due to $\mathrm{Kr}$ diffusion from the interstitials. The shift of that release can be seen for the $100 \mathrm{keV}$ implanted sample spectra (Fig. 3).

\section{Conclusions}

The TDS measurements of krypton released from the $\mathrm{Kr}$ implanted Si samples were presented. The implantation energies varied in the range $100-200 \mathrm{keV}$. A relatively sharp peak (most probably as a result of the release from the pressurized gas bubbles in cavities) was observed in the range $\approx 1100-1400 \mathrm{~K}$ - higher than for lighter noble gases like He or Ar. The shift of the peak position with the implantation energy and TDS heating ramp rate was observed. Splitting of the peak into two parts suggests the presence of two states of $\mathrm{Kr}$ in the implanted Si. This may be e.g. cavities of different sizes or vacancies and vacancy clusters. The Redhead analysis of the lower peak shift provided estimations of desorption activation energy values which decrease from $\approx 2.5 \mathrm{eV}$ (100 keV implantation) down to $\approx 0.8 \mathrm{eV}$ (for $200 \mathrm{keV}$ ). The twofold $\mathrm{Kr}$ release was observed for the $200 \mathrm{keV}$ and $100 \mathrm{keV} \mathrm{Kr}^{+}$double-implanted sample, each of them corresponding approximately to that of single implantation. 
The larger shift of the $100 \mathrm{keV}$ implantation peak is a result of the increased $\mathrm{Kr}$ concentration and sample disorder. The increase of the $\mathrm{Kr}$ desorption activation energy up to $\approx 3.2 \mathrm{eV}$ for both releases is observed.

\section{References}

[1] A.A. van Gorkum, E.V. Kornelsen, Vacuum 31, 89 (1981).

[2] M. Zibrov, Yu. Gasparyan, S. Ryabtsev, A. Pisarev, Phys. Proced. 71, 83 (2015).

[3] M.H.J. 't Hoen, B. Tyburska-Püschel, K. Ertl, M. Mayer, J. Rapp, A.W. Kleyn, P.A. Zeijlmans van Emmichoven, Nucl. Fusion 52, 023008 (2012).

[4] V.Kh. Alimov, B. Tyburska-Püschel, S. Lindig, Y. Hatano, M. Balden, J. Roth, K. Isobe, M. Matsuyama, T. Yamanishi, J. Nucl. Mater. 420, 519 (2012).

[5] C. Porosnicu, A. Anghel, K. Sugiyama, K. Krieger, J. Roth, C.P. Lungu, J. Nucl. Mater. 415, S713 (2011).

[6] V. Raineri, M. Saggio, E. Rimini, J. Mater. Res. 15, 1449 (2000).

[7] A.A. Airapetov, L.B. Begrambekov, S.V. Vergazov, doi: A.A. Kuzmin, O.C. Fadina, P.A. Shigin, J. Surf. Investig. X-ray Synchr. Neutron Techn. 4, 567 (2010).

[8] E. Oliviero, M.L. David, M.F. Beaufort, J.F. Barbot, A. van Veen, Appl. Phys. Lett. 81, 4201 (2002).

[9] B. Pivac, O. Milat, P. Dubček, S. Bernstorff, F. Corni, C. Nobili, R. Tonini, Phys. Status Solidi A 198, 29 (2003).

[10] O. Morozov, V. Zhurba, I. Neklyudov, O. Mats, A. Rud, N. Chernyak, V. Progolaieva, Nanoscale Res. Lett. 10, 154 (2015).

[11] R. Hanada, S. Haito, CYRIC Reports 1994, 13 (1994).

[12] I. Carvalho, H. Schut, A. Fedorov, N. Luzginova, P. Desgardin, J. Sietsma, J. Phys. Conf. Series 443, 012034 (2013).

[13] S. Chang, T. Lin, T. Li, J. Nanomater. 2014, 690498 (2014).
[14] V. Venugopal, B.J. Thijsse, J. Phys. D Appl. Phys. 42, 165412 (2009).

[15] V.A. Belous, A.S. Kuprin, N.S. Lomino, V.D. Ovcharenko, E.N. Reshetnyak, O.M. Morozov, V.I. Zhurba, G.N. Tolmachova, Proc. NAP 1 , 04RES07 (2012).

[16] F. Corni, G. Calzolari, F. Gambetta, C. Nobili, R. Tonini, M. Zapparoli, Mater. Sci. Eng. B 71, 207 (2000).

[17] G.F. Cerofolini, G. Calzolari, F. Corni, S. Frabboni, C. Nobili, G. Ottaviani, R. Tonini, Phys. Rev. B 61, 10183 (2000).

[18] S. Godey, E. Ntsoenzok, T. Sauvage, A. van Veen, F. Labohm, M.F. Beaufort, J.F. Barbot, Mater. Sci. Eng. B 73, 54 (2000).

[19] P. Desgardin, M.-F. Barthe, E. Ntsoenzok, C.-L. Liu, Appl. Surf. Sci. 252, 3231 (2006).

[20] R. Blackburn, Metall. Rev. 11, 159 (1966).

[21] W.M. Lau, I. Bello, L.J. Huang, X. Feng, M. Vos, I.V. Mitchell, J. Appl. Phys. 74, 7101 (1993).

[22] A. Filius, A. van Veen, K.R. Bijkerk, J.H. Evans, $R a-$ diat. Eff. 108, 1 (1989).

[23] R. Hanada, S. Saito, S. Nagata, S. Yamaguchi, T. Shinozuka, I. Fujioka, Mater. Sci. Forum 196-201, 1375 (1995).

[24] A. Drozdziel, A. Wojtowicz, M. Turek, K. Pyszniak, D. Maczka, B. Slowinski, Y.V. Yushkevich, J. Żuk, Acta Phys. Pol. A 125, 1400 (2014).

[25] M. Turek, A. Droździel, K. Pyszniak, A. Wójtowicz, D. Mączka, Y. Yuschkevich, Y. Vaganov, J. Żuk, Acta Phys. Pol. A 128, 849 (2015).

[26] J.F. Ziegler, M.D. Ziegler, J.P. Biersack, Nucl. Instrum. Methods Phys. Res. B 268, 1818 (2010).

[27] H. Assaf, E. Ntsoenzok, M.-F. Barthe, E. Leoni, M.O. Ruault, S. Ashok, MRS Proc. 994, F06-04 (2007).

[28] P.A. Redhead, Vacuum 12, 203 (1962). 